\title{
Polymeric enteral diets as primary treatment of active Crohn's disease: a prospective steroid controlled trial
}

\author{
F González-Huix, R de León, F Fernández-Bañares, M Esteve, E Cabré, D Acero, \\ A Abad-Lacruz, M Figa, M Guilera, R Planas, M A Gassull
}

\begin{abstract}
Thirty two patients with active Crohn's disease were included in a controlled randomised trial to determine the efficacy and safety of polymeric enteral nutrition compared with steroids, to achieve and maintain clinical remission. The polymeric diet was administered through a fine bore nasogastric tube by continuous, pump assisted infusion ( 2800 (SEM 120) kcal/day). The steroid group received $1 \mathrm{mg} / \mathrm{kg} /$ day of prednisone. Both treatments were effective in inducing clinical remission: 15 of the 17 patients given steroids and 12 of the 15 patients assigned to the polymeric diet went into clinical remission (defined by a Van Hees index $<120$ ) within four weeks of treatment. The percentage reduction of the Van Hees index was 34.8 (4.9)\% for steroids and $32.3(5) \%$ for enteral nutrition (mean difference $2 \cdot 5 \% ; 95 \% \mathrm{CI}-11 \cdot 8 \%$ to $+16 \cdot 8 \%$ ). Mean time elapsed to achieve remission was similar in both groups $(2.0(1) v 2.4(1.2)$ weeks). Tolerance of the enteral diet was excellent. Four patients in the steroid group had mild complications attributable to this treatment. Ten patients $(66.6 \%)$ in the steroid group and five $(41.6 \%)$ in the enteral nutrition group relapsed within a year of discharge, but no differences were found in the cumulative probability of relapse during the follow up period. These results suggest that polymeric enteral nutrition is as safe and effective as steroids in inducing short term remission in active Crohn's disease. (Gut 1993; 34: 778-782)
\end{abstract}

Elemental (aminoacid based) diets were initially introduced as primary treatment of active Crohn's disease because of their hypoallergenicity, because it was considered that whole protein may act as a dietary antigen and increase the immune stimuli to the gut. ${ }^{1}$ Another argument for these diets was their possible role in favouring bowel rest. Six prospective randomised trials have evaluated the efficacy of elemental diets in Crohn's disease. In four of them, the elemental diet was as effective as steroid treatment in achieving short term remission. $^{1-4}$ In one trial, elemental feeding was as effective as bowel rest plus total parenteral nutrition, ${ }^{5}$ but these results could not be reproduced in patients with colonic Crohn's disease. ${ }^{8}$

Recent studies suggest that the effectiveness of elemental formulas is sustained by factors other than the so called bowel rest. ${ }^{78}$ Also, polymeric (whole protein based) diets, when used as adjuncts to steroids, are well tolerated in active Crohn's disease. ${ }^{9}$ Elemental diets have the inconvenience, however, of being unpalatable, hyper- osmolar, and expensive. Therefore, other types of formula diets without such drawbacks have been assessed. In one study, hydrolysed (peptide based) diets were no better than steroid plus sulfasalazine treatment. ${ }^{10}$ In another trial this type of diet was as effective as an elemental diet in inducing remission in active Crohn's disease." Four prospective randomised trials have investigated the role of polymeric formulas in Crohn's disease. In three of them, this diet was as effective as an elemental diet in achieving remission. ${ }^{12-14}$ By contrast, opposite results were obtained in a recent study, with a very poor response to the polymeric diet. ${ }^{15}$ Thus the question of which type of enteral formula diet is better in the treatment of Crohn's disease remains open, and a study comparing polymeric diets with steroid treatment has, to our knowledge, never been performed.

The aim of the present study was to evaluate the efficacy and safety of polymeric enteral nutrition, as compared with steroid treatment, in achieving and maintaining clinical remission in patients with active Crohn's disease.

\section{Patients and methods}

From November 1988 until November 1991, all adult patients admitted because of clinically symptomatic Crohn's disease were prospectively evaluated. The diagnosis of the disease was based on previously reported clinical, morphological, and histopathological data. ${ }^{16}$ Patients were considered for the trial on the basis of: (1) symptoms consistent with activity of the disease (abdominal pain, diarrhoea, weight loss, anorexia, fever); (2) two or more abnormal laboratory indices indicative of active disease (erythrocyte sedimentation rate (ESR) $>30 \mathrm{~mm} / \mathrm{h}$, haemoglobin concentration $(\mathrm{Hb})<12 \mathrm{~g} / \mathrm{dl}$ for men and $<11.5 \mathrm{~g} /$ dl for women, C-reactive protein (CRP) $>3 \mathrm{mg} / \mathrm{l}$, platelet count $>350000$ cells $\left./ \mathrm{mm}^{3}\right)$; and (3) Van Hees activity index (VHAI $)^{17}$ greater than 120.

Patients were excluded from the study if they were already taking steroids, had evidence of intestinal perforation, significant intestinal obstruction, toxic megacolon, massive gastrointestinal haemorrhage, or mid-jejunal fistulas that precluded the use of enteral nutrition.

Forty four patients with Crohn's disease were examined for eligibility during the trial period Twelve were excluded because of VHAI $<120$ (five patients), steroid treatment (four patients), refusal to participate in the study (two patients), and mental retardation (one patient). Thus 32 patients (17 men, 15 women) were assigned by means of a random number table to one of two treatment groups: 17 patients were treated with 
TABLE I Composition of the polymeric formula diet *

\begin{tabular}{lc}
\hline Proteins (g/l) & $54 \cdot 60(22 \%)$ \\
Lipids $(\mathrm{g} / \mathrm{l})$ & $36 \cdot 20(32 \%)$ \\
Carbohydrates $(\mathrm{g} / \mathrm{l})$ & $114 \cdot 20(46 \%)$ \\
Energy content & $1 \mathrm{kcal} / \mathrm{ml}$ \\
Energy-nitrogen ratio (non-protein $\mathrm{kcal} / \mathrm{g} \mathrm{N})$ & $91 \cdot 5$ \\
Nitrogen $(\mathrm{g} / \mathrm{l})$ & $8 \cdot 73$ \\
Osmolality $(\mathrm{mOsm} / \mathrm{kg})$ & 278 \\
Energy source & Intact milk protein \\
Nitrogen & $13 \% \mathrm{MCT}, 28 \%$ saturates, $41 \%$ monounsaturates, \\
Fat & $18 \%$ polyunsaturates \\
Carbohydrate & Maltodextrins \\
Daily energy supply (kcal/day) & $2800(120)$ \\
Daily N supply (g N/day) & $24 \cdot 3(1 \cdot 5)$ \\
\hline
\end{tabular}

${ }^{\star}$ Edanec HN (UNIASA, Granada, Spain). Vitamin and trace element content in the upper limit of the recommended daily allowance for $2000 \mathrm{kcal}$.

MCT = Medium chain triglycerides. considered unsuccessful when clinical remission was not achieved after four weeks.

Laboratory evaluation, including complete haematological and biochemical analysis (SMA21 plus autoanalyser), was obtained weekly. Nutritional assessment was performed weekly by recording body weight, percentage of ideal body weight (\% IBW), mid-arm muscle circumference (MAMC, \% standard), triceps skinfold thickness (TSF, \% standard), and serum albumin concentration. ${ }^{19}$

\section{FOLLOW UP}

After remission was achieved, a western type lactose free oral diet was reintroduced in the PEN group within a period no longer than two days. In both groups, treatment with oral 5-ASA (500 mg mesalazine thrice daily) was started before discharge and maintained during follow up. Patients treated with steroids continued the decreasing steroid regime on an ambulatory basis and also had a western type lactose free oral diet. Milk derivatives were slowly reintroduced after one month of follow up in both groups.

Follow up included monthly visits during the first three months, and every three months afterwards. Relapse was defined as: (1) appearance of symptoms of flare up (abdominal pain or diarrhoea) or development of complications of the disease (intestinal occlusion, abdominal mass, fistulas etc); (2) two or more of body temperature $>37 \cdot 5^{\circ} \mathrm{C}, \mathrm{ESR}>30 \mathrm{~mm} / \mathrm{h}, \mathrm{CRP}>3$ $\mathrm{mg} / \mathrm{l}$, platelet count $>350000$ cells $/ \mathrm{mm}^{3}$.

hours/day No oral food or fluids were allowed during the trial. Daily total caloric requirements were calculated from Long's equation modified for ideal body weight. ${ }^{18} \mathrm{~A}$ starter regimen was used, with infusion of $60 \%$ of the calculated total caloric requirements on the first day; this was progressively increased to $100 \%$ by the third day.

Patients randomised for steroid treatment received oral prednisone ( $1 \mathrm{mg} / \mathrm{kg} / \mathrm{day})$. If improvement was achieved, prednisone was gradually reduced by $10 \mathrm{mg}$ weekly decrements down to $30 \mathrm{mg}$. Afterwards, prednisone was reduced in steps of $5 \mathrm{mg} /$ week until completely withdrawn. While in hospital, patients taking steroids were encouraged to eat the whole hospital lactose free diet (mean daily caloric intake 2200 (230) kcal/day).

In both groups, treatment with sulfasalazine, azathioprine, cyclosporine $\mathrm{A}$, or parenteral nutrition was not allowed. Two patients, one in each group, received oral metronidazole (20 $\mathrm{mg} / \mathrm{kg} /$ day) for severe perianal disease.

\section{EVALUATION OF RESPONSE}

Improvement was defined as showing three or less stools a day, absence or mild abdominal pain, no fever, pulse rate $\leqslant 90$ beats $/ \mathrm{min}$, and a $10 \%$ reduction in the VHAI in each weekly evaluation of the patient. Clinical remission was considered when a patient fulfilled the criteria of improvement and had a VHAI $<120$.

Patients not fulfilling the criteria of improvement, and those in whom the VHAI increased compared with that of the previous weekly evaluation, were considered as treatment failure and treatment was stopped. Also, treatment was

\section{STATISTICAL CALCULATIONS}

A sample size of 15 patients for each group was calculated based on an $\alpha$ error of 0.05 and a $\beta$ error of $0 \cdot 10$ (two tailed). ${ }^{20}$ This number of patients should allow us to detect a minimal relevant difference in the mean percentage reduction of the VHAI between both treatments of $20 \%$ ( 35 points); the estimated standard deviation of the VHAI is 30 points, a value obtained from a previous study on patients with similar clinical characteristics. ${ }^{21}$

The results are expressed as mean (SEM). The $95 \%$ confidence intervals ( $95 \%$ CIs) for percentages and for the difference between means were computed when appropriate. Significant differences between both groups were determined by the $\chi^{2}$ test of independence or Fisher's exact test and by the unpaired Student $t$ test for qualitative and quantitative data respectively. The effect of treatment on laboratory and anthropometric measurements was assessed by the paired Student $t$ test. Evolution of ordered categorical data in each group was assessed by the Wilcoxon rank sum test. Probability of relapse curves were computed by the Kaplan-Meier method, and were compared between groups by the long rank test. All the statistical analyses were performed with the statistical package BMDP (Statistical Software Inc, Los Angeles, CA, 1989).

\section{Results}

Table II shows the main features in both treatment groups. At entry, both groups were clinic- 
TABLE II Clinical and nutritional features of the patients at the beginning of the study

\begin{tabular}{lcc}
\hline & $\begin{array}{c}P E N \\
(n=15)\end{array}$ & $\begin{array}{c}\text { Steroids } \\
(n=17)\end{array}$ \\
\hline Age (y) & $31 \cdot 1(4 \cdot 1)$ & $32 \cdot 4(3 \cdot 7)$ \\
Sex (man/woman) & $7 / 8$ & $10 / 7$ \\
No of patients: & 7 & 11 \\
First attack & $3 / 3 / 9$ & $5 / 3 / 9$ \\
Location (colon/small bowel/mixed) & 3 & 5 \\
Extraintestinal complications & 4 & 4 \\
Perianal disease & 5 & 6 \\
Abdominal mass & $2 \cdot 6(0 \cdot 4)$ & $2 \cdot 8(0 \cdot 6)$ \\
No of bowel actions & 6 & 10 \\
Abdominal pain & $172 \cdot 5(7 \cdot 7)$ & $184 \cdot 3(9 \cdot 5)$ \\
Van Hees activity index & $36 \cdot 9(0 \cdot 1)$ & $36 \cdot 9(0 \cdot 1)$ \\
Temperature ( $\left.{ }^{\circ} \mathrm{C}\right)$ & $85 \cdot 1(2 \cdot 5)$ & $83 \cdot 8(2 \cdot 4)$ \\
Pulse rate (beats/min) & $38 \cdot 3(5 \cdot 8)$ & $47 \cdot 7(5 \cdot 4)$ \\
ESR (mm/h) & $37 \cdot 1(6 \cdot 1)$ & $44 \cdot 1(7 \cdot 8)$ \\
CRP(mg/) & $57 \cdot 1(3 \cdot 4)$ & $57 \cdot 8(3 \cdot 3)$ \\
Body wt (kg) & $11 \cdot 7(2 \cdot 9)$ & $11 \cdot 7(1 \cdot 7)$ \\
Body wt loss (\%) & $89 \cdot 1(3 \cdot 6)$ & $86 \cdot 9(3 \cdot 1)$ \\
\% IBW & $67 \cdot 5(7 \cdot 8)$ & $72 \cdot 9(7 \cdot 9)$ \\
TSF (\%) & $108 \cdot 1(2 \cdot 9)$ & $96 \cdot 5(5 \cdot 2)$ \\
MAMC(\%) & $34 \cdot 2(1 \cdot 2)$ & $33 \cdot 6(1 \cdot 4)$ \\
Serum albumin (g/l) & $2099(220)$ & $1674(150)$ \\
Lymphocytes (cells/mm ${ }^{3}$ ) & & \\
\hline
\end{tabular}

Values followed by parentheses are means (SEM).

PEN = Polymeric enteral nutrition; IBW = ideal body weight; $T S F=$ triceps skinfold; $M A M C=$ midarm muscle circumference; there were no significant differences between groups.

ally and nutritionally comparable. The number of patients with abnormal biological and nutritional indices before and after the trial were similar in both treatment groups (Table III).

Twenty seven patients achieved clinical remission: 15 out of $17(88 \cdot 2 \%$; $95 \%$ CI $63 \cdot 5-98 \cdot 5)$ in the steroid group, and 12 out of $15(80 \% ; 95 \% \mathrm{CI}$ $51 \cdot 9-95 \cdot 7)$ in the PEN group $(p=0 \cdot 43)$. Mean time to achieve remission was similar in both groups (steroids: $2 \cdot 0(1 \cdot 0)$ weeks $v$ PEN: $2 \cdot 4$ $(1 \cdot 2)$ weeks; $p=0 \cdot 47)$. Nine cases achieved a response within the first week (five prednisone, four PEN), eight cases by the second week (six prednisone, two PEN), five by the third week (two prednisone, three PEN), and five by the fourth week (two prednisone, three PEN). A decrease in activity of disease was shown in both groups by reduction in the VHAI (PEN: $172 \cdot 5$ (7.7) to $113.8(6.9), \mathrm{p}=0.0001$; steroids: 184.3 $(9.5)$ to $118 \cdot 1(10.6), \mathrm{p}=0.0003)$. The percent reduction of the VHAI was $34 \cdot 8(4 \cdot 9) \%$ for the steroid group and $32.28(5.0) \%$ for the PEN group. The $95 \% \mathrm{CI}$ for the difference of $2.5 \%$ ranged from $-11 \cdot 8 \%$ to $16 \cdot 8 \%$ and included zero. Tables IV and V show that the changes in the VHAI in both groups were due to the improvement in most items included in the index. Also, CRP concentration significantly decreased in both treatment groups.

Treatment failure occurred in two patients of the steroid group, both within the first week. One of them had an intestinal perforation and required surgery. The second patient was treated with enteral diet and achieved remission. In the

TABLE III Number of patients with abnormal biological and nutritional indices before and after the trial

\begin{tabular}{lrrrrr}
\hline & \multicolumn{2}{c}{$P e n(n=15)$} & & \multicolumn{2}{c}{ Steroids $(n=17)$} \\
\cline { 2 - 3 } \cline { 5 - 6 } & Initial & Final & & Initial & Final \\
\hline CRP $>3 \mathrm{mg} / 1$ & 14 & 11 & 15 & 11 \\
ESR $>30 \mathrm{~mm} / \mathrm{h}$ & 11 & 4 & 12 & 5 \\
Serum albumin $<33 \mathrm{~g} / 1$ & 6 & 1 & 7 & 2 \\
Platelets $>350 \times 10^{9} / 1$ & 9 & 6 & 13 & 12 \\
Hb $<12$ g/l men, $<11 \cdot 5 \mathrm{~g} / 1$ women & 8 & 7 & 9 & 8 \\
TSF $<5$ th $\mathrm{P}^{\star}$ & 5 & 4 & 5 & 4 \\
MAMC $<5$ th $\mathrm{P}^{\star}$ & 3 & 4 & 4 & 3 \\
Body wt loss $>10 \%$ & 8 & 6 & 10 & 10 \\
\hline
\end{tabular}

$\star 5$ th $P=5$ th percentile of the healthy standards for age and sex. ${ }^{19}$

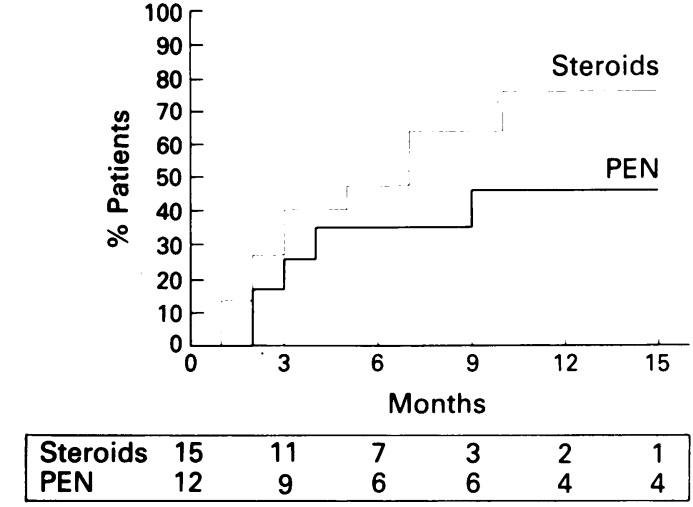

Cumulative probability of relapse during follow up in both groups (log rank test, $p=0 \cdot 21)$. Both groups were taking mesalazine $(1 \cdot 5 \mathrm{~g} /$ day $)$.

PEN group, there were three treatment failures. One of these patients improved when steroids were administered. The remaining two patients did not achieve remission after four weeks of treatment. They also failed to respond to steroids and were treated surgically. No preferential disease location was noted in treatment failures.

Protein-energy nutritional status was maintained in both groups during the trial period. Nutritional support induced a significant increase in TSF, whereas normal hospital diet plus steroids did not. Similar significant increases in serum albumin concentration were found in both groups (Table V).

Tolerance of the diet in the PEN group was excellent. One patient complained of heartburn and required the administration of $\mathrm{H}_{2}$ antagonists to relieve it. It is remarkable that no patient had diarrhoea attributable to diet intolerance, and the number of bowel movements decreased significantly in the PEN group (Table IV). Four of the $17(23.5 \%)$ patients in the steroid group had complications attributable to the treatment (two moon faces, one acne, and one hypokalaemia), but no difference in treatment related complication rate was found between groups $(\mathrm{p}=\mathbf{0} \cdot 21)$.

Fifteen patients relapsed during the follow up, 10 from the steroid group $(66 \cdot 6 \%)$ and five from the PEN group (41.6\%). No differences were found in the cumulative relapse probability during follow up ( $p=0 \cdot 21$ ) (figure). Follow up in non-relapsing patients ranged from two to $41 \cdot 7$ months (median $9 \cdot 1$ months) in the PEN group, and from 3.2 to 30.1 months (median $7 \cdot 8$ months) in the steroid group.

\section{Discussion}

To our knowledge, this is the first controlled trial to compare a polymeric formula enteral diet $v$ steroids in the treatment of active Crohn's disease. The results suggest that polymeric diets are as safe and effective as steroids in inducing short term remission. The mean difference of reduction in the VHAI between treatments was small. Also, there is only a probability of 0.025 that the true difference between treatment groups in the population was greater than $16.8 \%$ (upper limit of $95 \% \mathrm{CI}$ ). So it is unlikely that clinically important differences have been overlooked. 
TABLE IV Changes in clinical and biological indices during the trial

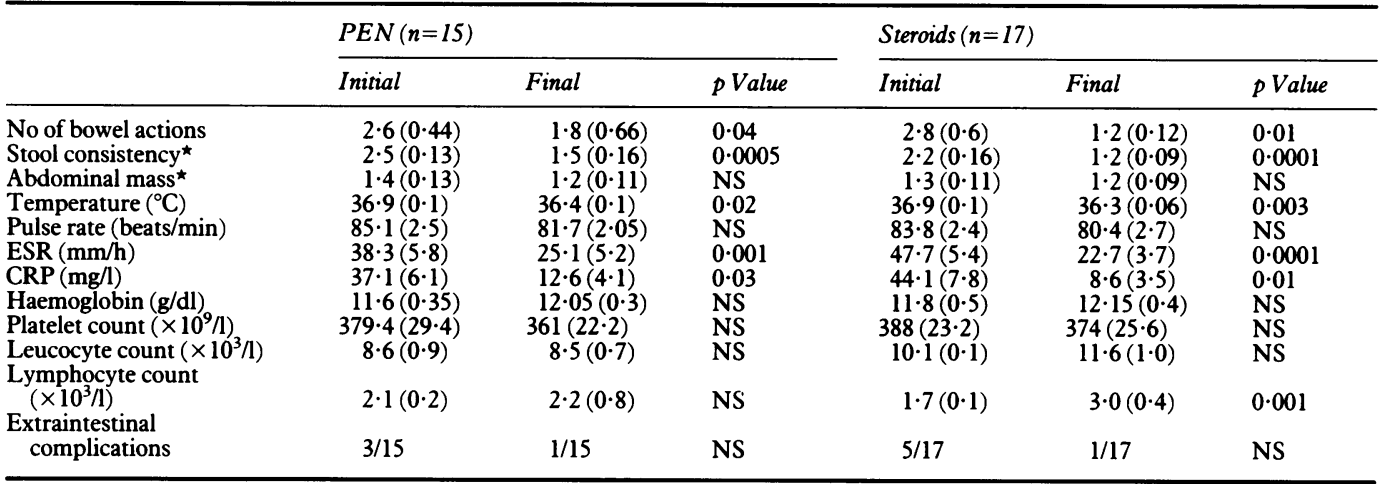

^Scores as expressed in the Van Hees activity index.

Values followed by parentheses are means (SEM).

Changes in the VHAI were used as an end point in this study. This index, as it largely depends on laboratory measurements, is more objective than other indices including overall clinical assessment, such as the Crohn's disease activity index (CDAI). ${ }^{22-24}$ Also, the increase in the number of liquid or soft stools, an important item of CDAI, may be caused either because of worsening of the intestinal disease or as a side effect of enteral nutrition. This may induce misjudgment. Moreover, the use of the reduction of the VHAI instead of CDAI as the end point to calculate the sample size allowed us to study a smaller sample of patients than in previous work,,$^{10}$ for the same $\alpha$ and $\beta$ errors. This is due to the smaller variability of VHAI compared with CDAI. ${ }^{22-24}$

In a unique trial comparing a non-elemental tube fed diet with steroids, Lochs et al suggested that a peptide based diet was less effective than a combination of methylprednisolone and sulfasalazine in treating active Crohn's disease. ${ }^{10}$ The different results obtained with the polymeric diet used in our study are unlikely to be a consequence of the different protein composition. Peptides, less antigenic substrates than whole protein, are effective in inducing remission in Crohn's disease. ${ }^{11}$ Thus differences should be attributed to other factors. As previously mentioned, the use of CDAI as the criteria to assess clinical efficacy in the study of Lochs et al may be controversial due to the importance of the number of bowel movements on the CDAI score. The osmolality of the diet used was high (400 $\mathrm{mOsm} / \mathrm{kg}$ ) because, as well as peptides, it contained medium chain triglycerides $(60 \%$ of the fat content). Thus this formula diet might increase stool frequency and cause misleading changes in the CDAI.

Our present study supports the view that whole protein based diets are clinically effective, as suggested in three previous trials that compared this type of diet with elemental formulas, ${ }^{12-14}$ although in one of them ${ }^{13}$ the sample is small and the conclusions are only indicative. Only in one study, by Giaffer et al, was a poorer response found with a polymeric diet compared with an elemental diet. ${ }^{15}$ In this trial the polymeric diet was discontinued for ethical reasons when no improvement was found by the 10th day of treatment. The results of this trial can be questioned for several reasons. Firstly, the groups studied were not homogeneous for the location of the disease. This could have been avoided by stratified randomisation of the patients. Secondly, if the objective of the study of Giaffer $e t$ al was to ascertain whether a particular form of nitrogen source (amino acid $v$ whole protein) had a primary beneficial effect, both formula diets should have been equivalent in carbohydrate and fat composition, and in fact the amount of fat administered was 15 times higher in the polymeric than in the elemental diet.

Nutritional improvement itself does not seem to have had a role in the effect of PEN in our study. Although mean TSF increased significantly in the PEN group, this improvement is likely to be clinically irrelevant as no differences were found in the number of patients with abnormal TSF values before and after the trial. The increase in serum albumin was similar in both groups. Therefore, the effect of PEN seems to be mediated by changes in the inflammatory activity. In fact, biological indices of inflammation (CRP, ESR) improved similarly in both groups.

One fact seldom taken into account when comparing diets in the treatment of Crohn's disease is the possible differences in their fat

TABLE V Changes in nutritional indices during the trial

\begin{tabular}{|c|c|c|c|c|c|c|}
\hline & \multicolumn{3}{|l|}{$\operatorname{PEN}(n=15)$} & \multicolumn{3}{|c|}{ Steroids $(n=17)$} \\
\hline & Initial & Final & $p$ Value & Initial & Final & p Value \\
\hline $\begin{array}{l}\text { Body weight }(\mathrm{kg}) \\
\text { IBW }(\%) \\
\text { TSF }(\%) \\
\text { MAMC }(\%) \\
\text { Serum albumin }(\mathrm{g} / \mathrm{l})\end{array}$ & $\begin{array}{r}57 \cdot 1(3 \cdot 4) \\
89 \cdot 1(3 \cdot 6) \\
67 \cdot 5(7 \cdot 9) \\
108 \cdot 1(2 \cdot 9) \\
34 \cdot 2(1 \cdot 2)\end{array}$ & $\begin{array}{c}58 \cdot 3(3 \cdot 2) \\
91 \cdot 1(3 \cdot 3) \\
73 \cdot 4(6 \cdot 8) \\
102 \cdot 2(6 \cdot 9) \\
39 \cdot 2(1 \cdot 1)\end{array}$ & $\begin{array}{l}\text { NS } \\
\text { NS } \\
0 \cdot 03 \\
\text { NS } \\
0 \cdot 006\end{array}$ & $\begin{array}{l}57 \cdot 8(3 \cdot 3) \\
86 \cdot 9(3 \cdot 9) \\
72 \cdot 9(7 \cdot 9) \\
96 \cdot 5(5 \cdot 2) \\
33 \cdot 6(1 \cdot 4)\end{array}$ & $\begin{array}{r}58 \cdot 2(3 \cdot 5) \\
87 \cdot 4(4 \cdot 1) \\
74 \cdot 5(7 \cdot 7) \\
101 \cdot 8(3 \cdot 0) \\
37 \cdot 8(1 \cdot 4)\end{array}$ & $\begin{array}{l}\text { NS } \\
\text { NS } \\
\text { NS } \\
\text { NS } \\
0 \cdot 01\end{array}$ \\
\hline
\end{tabular}

Values are means (SEM). For abbreviations see table II. 
composition. Experimental work has been reported in which the administration of low fat diets $^{25}$ or diets with low essential fatty acid content ${ }^{26}$ have an immunomodulatory effect in animal models. Also, essential fatty acid deficiency diminishes acute inflammation ${ }^{27}$ and improves experimental colitis in rats. ${ }^{28}$ Recent studies in vitro and in humans emphasise the possible role of fatty acids and their derivatives in mediating inflammation..$^{29-31}$ In this context, an altered plasma pattern of polyunsaturated fatty acids has been described in inflammatory bowel disease. ${ }^{32}$

A careful examination of the reports of elemental diets having a favourable effect on Crohn's disease, ${ }^{1-5}$ indicates that all of them had very low fat content $(0.6$ to $1.3 \%$ of total calories). When intermediate or high fat diets are used, ${ }^{12-15}$ the favourable or unfavourable clinical outcome might depend on the type of predominant fatty acids. In the present study, the polymeric diet used had both high fat $(33 \%$ of the total calories) and high monounsaturated fatty acid (oleic acid) content. By contrast, the polymeric diet used in the study of Giaffer et al was high fat ( $36 \%$ of total calories) but also high in linoleic acid. This fatty acid is the precursor of arachidonic acid, which, in turn is the substrate for eicosanoid $\left(\mathrm{LTB}_{4}, \mathrm{TxA}_{2}, \mathrm{PGE}_{2}\right.$ ) synthesis. Thus quantitative or qualitative differences in the lipid composition of the administered fat, saturated or monounsaturated $v$ polyunsaturated oils, may modify the synthesis of eicosanoids and impair some immunomodulatory mechanisms that may influence the outcome when treating active Crohn's disease. Studies taking into account the lipid composition of the diets may help to further define the mechanism for the primary effect of enteral diets in active Crohn's disease.

In our present study, differences in relapse during follow up between both groups were not found, but relapse rate tended to be lower in the PEN group. This suggests that the remissions achieved with PEN were real, whatever the mechanism. This trend has to be confirmed with more patients and a longer follow up.

In conclusion, the results of our present study suggest that polymeric diets are a safe and effective treatment for active Crohn's disease. They are a well tolerated and a cheaper alternative to elemental diets, which merit serious consideration as treatment of active Crohn's disease, specially in malnourished patients or when steroid treatment is contraindicated. Further studies in a larger series are needed to ascertain which subgroups of patients with Crohn's disease are more prone to respond to diet treatment and to maintain longterm remission.

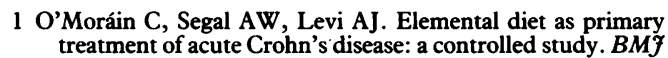
1984; 288: 1859-62

2 Seidman EG, Bouthillier L, Weber AM, Roy CC, Morin CL. Elemental diet versus prednisone as primary treatment of Crohn's disease. Gastroenterology 1986; 90: A1625.

3 Saverymuttu S, Hodgson HJF, Chadwick VS. Controlled trial comparing prednisolone with an elemental diet plus nonabsorbable antibiotics in active Crohn's disease. Gut 1985; 26: 994-8.

4 Hunt JB, Payne-James JJ, Palmer KR, Kumar PK, Clark $M L$, Farthing MJG, et al. A randomized controlled trial of elemental diet and prednisolone as prmary therapy in acute A224.
5 Alun Jones V. Comparison of total parenteral nutrition and elemental diet in induction of remission of Crohn's disease. Long-term maintenance of remissions by personalized food exclusion diets. Dig $D$ is $S c i$ 1987; 32 (suppl): $100 \mathrm{~S}-7 \mathrm{~S}$.

6 Rigaud D, Cerf M, Melchior JC, Sautier C, René E, Mignon M. Nutritional assistance (NA) and acute attacks of Crohn's $M$. Nutritional assistance (NA) and acute attacks of Crohn's
disease (CD): Efficacy of total parenteral nutrition (TPN) as disease (CD): Efficacy of total parenteral nutrition (TPN) as compared with elemental (EEN) and polymeric

7 Lochs H, Meryn S, Marosi L, Ferenci P, Hortnag H. Has total bowel rest a beneficial effect in the treatment of Crohn's disease? Clin Nutr 1983; 2: 61-4.

8 Greenberg GR, Fleming CR, Jeejeebhoy JN, Rosenberg IH, Sales D, Tremaine WJ. Controlled trial of bowel rest and nutritional support in the management of Crohn's disease. Gut 1988; 29: 1309-15.

9 Gassull MA, Abad A, Cabré E, González-Huix F, Giné JJ, Dolz C. Enteral nutrition in inflammatory bowel disease. Dolz C. Enteral nutrition

10 Lochs H, Steinhardt HJ, Klaus-Wentz B, Zeitz M, Vogelsang $\mathrm{H}$, Sommer $\mathrm{H}$, et al. Comparison of enteral nutrition and drug treatment in active Crohn's disease. Results of the European Cooperative Crohn's disease study IV. Gastroenterology 1991; 101: 881-8.

11 Middleton SJ, Riordan AM, Hunter JO. Comparison of elemental and peptide-based diets in the treatment of actue Crohn's disease. Italian foumal of Gastroenterology 1991; 23: Crohn's
609.
Raouf

12 Raouf AH, Hildrey V, Daniel J, Walker RJ, Krasner N, Elias $\mathrm{E}$, et al. Enteral feeding as sole treatment for Crohn's disease: controlled trial of whole protein $v$ amino acid based feed and a case study of dietary challenge. Gut 1991; 32: f02-7.

13 Park RHR, Galloway A, Danesh BJZ, Russell RI. Doubleblind controlled trial of elemental and polymeric diets as primary therapy in active Crohn's disease. Eur 7 Gastro enterol Hepatol 1991; 3: 483-90.

14 Rigaud D, Cosnes J. Le Quintrec Y, René E, Gendre JP Mignon M. Controlled trial comparing two types of enteral nutrition in treatment of active Crohn's disease: elemental $v$ polymeric diet. Gut 1991; 32: 1492-7.

15 Giaffer MH, North G, Holdsworth CD. Controlled trial of polymeric versus elemental diet in treatment of active Crohn's disease. Lancet 1990; 335: 816-9.

16 Donaldson Jr RM. Crohn's disease. In: Sleisenger MH, Fordtran JS, eds. Gastrointestinal disease. Philadelphia: WB Saunders, 1989: 1327-58.

17 Van Hees PAM, Van Elteren RH, Van Lier HJJ, Van Tongeren JHM. An index of inflammatory activity in patients with Crohn's disease. Gut 1980; 21 : 279-86.

18 Cabré E, Gassull MA. Enteral tube-feeding in digestive tract diseases: a pathophysiological challenge. $\mathcal{f}$ Clin Nutr Gastroenterol 1986; 1: 97-102.

19 Gassull MA, Cabré E, Vilar L, Alastrue A, Montserrat A. Protein-energy malnutrition: an integral approach and a Protein-energy malnutrition: an integral approach and a
simple new classification. Hum Nutr Clin Nutr 1984; 38C: simple new

20 Strike PW. Medical laboratory statistics. Bristol: Wright PSG, 1981.

21 Abad A, Cabré E, Giné JJ, Dolz C, González-Huix F, Xiol X, et al. Total enteral nutrition in hospitalized patients with inflammatory bowel disease. $\mathcal{F}$ Clin Nutr Gastroenterol 1986 1: $1-8$

22 DeDombal FT, Softley A. IOIBD report no 1: observer variation in calculating indices of severity and activity in Crohn's disease. Gut 1987; 28: 474-81.

23 Crama-Bohbouth G, Peña AS, Biedmond I, Verspaget HW, Blok D, Arndt JW, et al. Are activity indices helpful in Blok $\mathrm{D}$, Arndt $\mathrm{W}$, et al. Are activity indices helpful in Gut 1989; 30: 1236-40.

24 Singleton JW. Clinical activity assessment in inflammatory bowel disease. Dig Dis Sci 1987; 32: 42S-5S.

25 Morrow WJW, Homsy J, Swanson CA, et al. Dietary fat influences the expression of autoimmune disease in MLR $1 \mathrm{pr} / 1 \mathrm{pr}$ mice. Immunology 1986; 89: 439-43.

26 Schreiner GF, Flye W, Brunt E, et al. Essential fatty acid deplection of renal allografts and prevention of rejection. deplection of renal allografts 1988 ; 240: 1032-3.

27 Denko CW. Modification of adjuvant inflammation in rats deficient in essential fatty acids. Agents Actions 1976; 65: 636-41.

28 Lohoues MJ, Russo P, Gurbindo C, Roy C, Levy E, Lepage G, $e t$ al. Essential fatty acid deficiency improves the course of experimental colitis in the rat: Possible role of dietary immunomodulation. Gastroenterology 1992; 102: A655.

29 Strasser T, Fischer S, Weber PC. Leukotriene B5 is formed in human neutrophils after dietary supplementation with eicosape $1540-3$.

30 Lee TH, Hoover RL, Williams JD, Sperling RI, Ravalese J, Spur BW, et al. Effect of dietary enrichment with eicosapentaenoic and docosahexaenoic acids on in vitro neutrophil and monocyte leukotriene generation and neutrophil function. N Engl F Med 1985; 312: 1217-24.

31 Endres S, Ghorbani R, Kelley VE, Georgilis K, Lonnemann $\mathrm{G}$, van der Meer JWM, et al. The effect of dietary supplementation with $\mathrm{n}-3$ polyunsaturated fatty acids on the synthesis of interluekin-1 and tumor necrosis factor by mononuclear cells. N Englf Med 1989; 320: 265-71.

32 Esteve $M$, Ramírez M, Fernández-Bañares F, Abad-Lacruz A, Gil A, Cabré E, et al. Plasma polyunsaturated fatty acid pattern in active inflammatory bowel disease. Gut 1992; 33: pattern 